\title{
Fine-tuning the cutpoint T-score as an epidemiological index with high specificity for osteoporosis: methodological considerations for the Chinese population
}

\author{
Yì Xiáng J. Wáng ${ }^{1 \wedge}$, Ben-Heng Xiao ${ }^{1 \wedge}$, Yi Su ${ }^{2}$ Jason C. S. Leung ${ }^{3}$, Patti M. S. Lam³ \\ Timothy C. Y. Kwok \\ ${ }^{1}$ Department of Imaging and Interventional Radiology, Faculty of Medicine, The Chinese University of Hong Kong, Hong Kong, China; ${ }^{2}$ Key \\ Laboratory of Molecular Epidemiology of Hunan Province, School of Medicine, Hunan Normal University, Changsha, Hunan, China; ${ }^{3}$ JC Centre \\ for Osteoporosis Care and Control, Faculty of Medicine, The Chinese University of Hong Kong, Hong Kong, China; ${ }^{4}$ Department of Medicine and \\ Therapeutics, Faculty of Medicine, The Chinese University of Hong Kong, Hong Kong, China
}

Correspondence to: Dr. Yì Xiáng J. Wáng. Department of Imaging and Interventional Radiology, The Chinese University of Hong Kong, Shatin, New Territories, Hong Kong, China. Email: yixiang_wang@cuhk.edu.hk.

Submitted Aug 24, 2021. Accepted for publication Nov 11, 2021.

doi: 10.21037/qims-21-845

View this article at: https://dx.doi.org/10.21037/qims-21-845

Osteoporosis is a skeletal disease characterized by low bone mass and microarchitectural deterioration of bone tissue with a consequent increase in bone fragility and susceptibility to fracture. The clinical significance of osteoporosis lies in the fractures which occur, and the most important fracture is hip fracture. Among Caucasian women, the lifetime risk of hip fracture at the age of 50 years is considered to be around $16 \%$, while $30 \%$ is a conservative estimate of the risk of any osteoporotic fractures (1). According to the WHO criteria, T-score is defined as: $\left(\mathrm{BMD}_{\text {patient }}-\mathrm{BMD}_{\text {young normal mean }}\right) / \mathrm{SD}_{\text {young normal population, }}$ where $\mathrm{BMD}$ is bone mineral density and $\mathrm{SD}$ is the standard deviation. In adult women, the cutpoint value of patient BMD 2.5 SD below $\mathrm{BMD}_{\text {young normal mean }}$ satisfies that, when the femoral neck is measured, osteoporosis prevalence is about $16.2 \%$ for those age $\geq 50$ years, the same as the lifetime risk of hip fragility fracture $(1,2)$. If other sites are also considered, this cutpoint value identifies approximately $30 \%$ of postmenopausal women as having osteoporosis, which is approximately equivalent to the lifetime risk of fragility fracture at the spine, hip, or forearm. It is considered that this portion of the population has a faster bone mass loss, and interventions should be taken ideally before a fragility fracture occurs. Therefore, the original WHO classification was intended for a populationbased prevalence with a classification of osteoporotic patients having T-score $\leq-2.5$ (1). The National Health and Nutrition Examination Survey (NHANES) provides a reference population for proximal femur BMD of Caucasians. East Asians generally have lower measured $\mathrm{BMD}$; thus, various region-specific reference databases have been published.

The osteoporotic fracture prevalence is substantially lower among Chinese compared to that of Caucasians, both for men and women. For example, Bow et al. (3) reported that the hip fracture rates for Hong Kong women aged 65 to 69 years old were $33 \%$ of those of the Caucasian women in the same age group. In the study of Shin et al. (4), the prevalence of self-reported non-traumatic fracture was US Caucasian men: $17.1 \%$; US Asian men: $10.5 \%$; and Hong Kong Chinese men: 5.6\%. Lauderdale et al. (5) estimated US national nontraumatic hip fracture incidence rates,

^ ORCID: Yì Xiáng J. Wáng, 0000-0001-5697-0717; Ben-Heng Xiao, 0000-0003-1575-1475. 
Table 1 Impact of hip fracture prevalence value on the estimation of cutoff T-score value and osteoporosis prevalence

\begin{tabular}{|c|c|c|c|c|c|c|c|c|c|c|c|c|}
\hline & $\mathrm{BMD}_{\text {young }}$ & $\mathrm{SD}_{\text {young }}$ & $\mathrm{BMD}_{\text {old }}$ & $\mathrm{SD}_{\text {old }}$ & \multicolumn{2}{|c|}{ T-score $\leq-2.5$} & \multicolumn{2}{|c|}{ 1/2 Caucasian rate ${ }^{\Uparrow}$} & \multicolumn{2}{|c|}{$40 \%$ Caucasian rate } & \multicolumn{2}{|c|}{ 1/3 Caucasian rate } \\
\hline Hong Kong & 0.890 & 0.110 & 0.7509 & 0.1100 & 0.6150 & $10.75 \% *$ & 0.5969 & -2.6645 & 0.5837 & -2.7845 & 0.5727 & -2.8845 \\
\hline China Mainland & 0.865 & 0.126 & 0.7002 & 0.1259 & 0.5500 & $11.7 \%$ & 0.5239 & -2.7071 & 0.5088 & -2.8270 & 0.4962 & -2.9270 \\
\hline Japan & 0.801 & 0.106 & 0.6569 & 0.0913 & 0.5360 & $11.6 \%$ & 0.5291 & -2.5651 & 0.5181 & -2.6689 & 0.5090 & -2.7547 \\
\hline
\end{tabular}

Hong Kong data, China mainland data, and Japan data are from Lynn et al. (14), Zeng et al. (15), and Iki et al. (16), respectively. China mainland data and Japan data are based on femoral neck bone mineral density (BMD). Hong Kong data are based on total hip BMD as there is no sufficient femoral neck BMD data available in the report of Lynn et al. BMD unit in $\mathrm{g} / \mathrm{cm}^{2}$. BMD $\mathrm{BMung}$, adopted value as the reference $\mathrm{BMD} ; \mathrm{SD}_{\text {young, }}$, standard deviation of the reference young subject data; $B M D_{\text {old }}$, measured $B M D$ of the subjects $\geq 50$ years old; $\mathrm{SD}_{\text {old }}$, standard deviation of the subjects $\geq 50$ years old; $\mathrm{BMD}_{\mathrm{os}}$, the cutpoint to define osteoporosis. \#, prevalence of osteoporosis according to the defining criterion of T-score $\leq-2.5$. *, osteoporosis prevalence listed in (14) is $16 \%$; based on the data provided we derived a prevalence of $10.75 \%$. Caucasian rate of hip fracture prevalence is assumed being $16 \%$, thus $1 / 2,40 \%$, and $1 / 3$ rate is $8 \%, 6.4 \%$, and $5.33 \%$ respectively. ", the value cited by (17) for Chinese.

reported the fracture ratio relative to Caucasians being 0.30 for Chinese women and 0.42 for Chinese men. Using the Canadian population-based Manitoba BMD Program registry data, Leslie et al. (6) reported that, at baseline 'prior fracture' was recorded in $20.1 \%$ of Caucasian women (mean age: 64.7 years) and $11.7 \%$ of Asian women (mostly Chinese and Filipino, mean age: 62.8 years). During followup $(8.8 \pm 5.1$ years for Caucasians and $6.5 \pm 5.0$ years for Asians), the incident hip fracture rate per 1,000 personyears was 3.6 for Caucasians and 0.6 for Asians. According to the New York State inpatient hip fracture data from 1988 to 2002, Fang et al. (7) reported that the annual ageadjusted hip fracture incidence rate per 100,000 was 459 and 230 in Caucasian women and men, and 174 and 104 in Asian American women and men. These data concur with the reports that elderly Chinese lose bone much more slowly. In a study comparing Caucasian Canadian and Chinese Canadian, Morin et al. (8) reported that, for the participants aged $>50$ years old at baseline, 5 -year total hip BMD change $\left(\mathrm{g} / \mathrm{cm}^{2}\right)$ was -0.000 for Chinese women and -0.013 for Caucasian women, -0.003 for Chinese men and -0.013 for Caucasian men. Sheu et al. (9) reported a USAbased study with an average follow-up of 4.6 years in 3,869 Caucasian and 145 Asian men aged $\geq 65$ years (mean ages: $73 \pm 5$ and $72 \pm 5$ years, respectively). The annual rate of decline in BMD at the femoral neck was $0.32 \%$ and $0.09 \%$ respectively for Caucasians and Asians.

Recent evidence suggests that, compared with Caucasians, the relative prevalence of osteoporotic vertebral fracture $(\mathrm{OVF})$ follows the same pattern as other clinical fractures $(10,11)$. One study shows Hong Kong Chinese women and Italian women (mean age both 74.1 years) had endplate and/or cortex OVF in $26 \%$ cases and $47 \%$ cases respectively; and 9.5\% Chinese women and 26\% Italian women had OVF with $\geq 40 \%$ height loss (11). In our MrOS (Hong Kong) and MsOS (Hong Kong) studies, from baseline on, clinical spine fractures (mostly fragility fractures) were followed up for 10 years for 1,954 male participants, and for 9 years for 1,953 female participants. Clinical spine fracture $\geq 1$ time (i.e., at least one fracture incident) were recorded 133 cases and 273 cases per 100,000 person-years in men and women, respectively $(11,12)$. In MrOS (USA) study which has the same enrolment strategy for participants as MrOS (Hong Kong, China) study, with 5,995 cases followed up for 4.7 years, Freitas et al. (13) recorded clinical spine fracture incidence of 216 cases $/ 100,000$ person-years.

As noted above, the cutpoint $\mathrm{T}$-score was set at $\leq-2.5$ primarily to satisfy the hip-based osteoporosis and hip fracture prevalence to be around $16 \%$ for the $\geq 50$ years old Caucasian women. However, for both the most important hip fracture and the most common OVF, the prevalence among Chinese is no more than half of those of Caucasians. Elderly Chinese also lose bone much more slowly. Thus, in addition to using a local reference database, an additional adjustment of cutpoint T-score for defining osteoporosis among elderly Chinese should be applied, rather than directly adopting the Caucasian cutpoint T-score. As a way of example, we used three female hip BMD reference databases of Hong Kong, China Mainland, and Japan (14-16), and tested cutpoint T-score adjustment (Table 1, Appendix 1). For the case of Hong Kong, if Chinese women's osteoporotic hip fracture prevalence is $40 \%$ of that of Caucasians, then the cutpoint T-score for defining 
hip osteoporosis can be better set at $\leq-2.78$. This would be in agreement with the classification of Hong Kong being a 'medium risk territory' for hip fracture (as opposed to the USA being a 'very high-risk' country) (17). The principle presented here can also apply to osteoporosis in men and other BMD measure sites such as the lumbar spine. In recent Canadian studies, it is noted that East Asians are more likely to be diagnosed with osteoporosis based on $\operatorname{BMD}(6,8)$.

The original osteoporosis T-score $\leq-2.5$ criterion aims at specificity (1). In the case of hip fracture, the WHO criterion targets high specificity (generally $80 \%$ ) for lifetime fracture risk at the expense of low sensitivity (generally about $30 \%$ ) (2). Many fractures will occur in individuals without osteoporosis, but overall fracture risk remains low in these subjects; while fracture risk is very high in individuals with osteoporosis. On the other hand, as well recognized, BMD alone is not optimal as an intervention threshold for many reasons. The significance of any given T-score to fracture risk depends on age and the presence of clinical risk factors. For any BMD, fracture risk is much higher in the elderly than in the young. With advancing age, the difference in the probability of fracture between the general population and those with a T-score of -2.5 SD diminishes. The intervention threshold depends upon risk, life expectancy, and the benefits and side effects of interventions. With the increasing development of effective agents and price reductions, the intervention threshold may be more relaxed for elderly people. Ideally, an intervention should be initiated prior to the diagnostic threshold being established, i.e., intervention should be more preventive. Fracture probability is used for the cost-effectiveness assessment of interventions. The most commonly used tool for fracture probability assessment is FRAX, which calculates the 10-year fracture risk (18). For the case in Hong Kong, Kwok et al. (19) recommended that all men (aged $\geq 70$ years) and women (aged $\geq 65$ years) with a fracture-risk assessment-derived 10-year risk (hip fracture with $\mathrm{BMD}) \geq 3 \%$ should receive $\geq 3$ years of antiosteoporotic treatment.

In conclusion, considering fragility risk is substantially lower in Chinese than Caucasians, we suggest that, in addition to using a local reference database, the T-score for defining osteoporosis should be adjusted accordingly as well. The suggested approach will be more in line with the original WHO definition of osteoporosis as a disease category and will allow a more meaningful international comparison of disease burden and epidemiological studies.

\section{Acknowledgments}

We thank Professor Brian C. Lentle, University of British Columbia, Victoria, Canada, for helpful comments.

Funding: None.

\section{Footnote}

Provenance and Peer Review: This article was a standard submission to the journal. The article has undergone external peer review.

Conflicts of Interest: All authors have completed the ICMJE uniform disclosure form (available at https://dx.doi. org/10.21037/qims-21-845). YXJW serves as the Editor-InChief of Quantitative Imaging in Medicine and Surgery. The other authors have no conflicts of interest to declare.

Ethical Statement: The authors are accountable for all aspects of the work in ensuring that questions related to the accuracy or integrity of any part of the work are appropriately investigated and resolved.

Open Access Statement: This is an Open Access article distributed in accordance with the Creative Commons Attribution-NonCommercial-NoDerivs 4.0 International License (CC BY-NC-ND 4.0), which permits the noncommercial replication and distribution of the article with the strict proviso that no changes or edits are made and the original work is properly cited (including links to both the formal publication through the relevant DOI and the license). See: https://creativecommons.org/licenses/by-nc-nd/4.0/.

\section{References}

1. Kanis JA. Assessment of fracture risk and its application to screening for postmenopausal osteoporosis: synopsis of a WHO report. WHO Study Group. Osteoporos Int 1994:4:368-81.

2. Kanis JA, McCloskey EV, Johansson H, Oden A, Melton LJ 3rd, Khaltaev N. A reference standard for the description of osteoporosis. Bone 2008;42:467-75.

3. Bow CH, Cheung E, Cheung CL, Xiao SM, Loong C, Soong C, Tan KC, Luckey MM, Cauley JA, Fujiwara S, Kung AW. Ethnic difference of clinical vertebral fracture risk. Osteoporos Int 2012;23:879-85.

4. Shin MH, Zmuda JM, Barrett-Connor E, Sheu Y, Patrick 
AL, Leung PC, Kwok A, Kweon SS, Nam HS, Cauley JA; Osteoporotic Fractures in Men (MrOS) Research Group. Race/ethnic differences in associations between bone mineral density and fracture history in older men. Osteoporos Int 2014;25:837-45.

5. Lauderdale DS, Jacobsen SJ, Furner SE, Levy PS, Brody JA, Goldberg J. Hip fracture incidence among elderly Asian-American populations. Am J Epidemiol 1997;146:502-9.

6. Leslie WD, Morin SN, Lix LM, McCloskey EV, Johansson H, Harvey NC, Kanis JA. Fracture prediction from FRAX for Canadian ethnic groups: a registry-based cohort study. Osteoporos Int 2021;32:113-22.

7. Fang J, Freeman R, Jeganathan R, Alderman MH. Variations in hip fracture hospitalization rates among different race/ethnicity groups in New York City. Ethn Dis 2004;14:280-4.

8. Morin SN, Berger C, Liu W, Prior JC, Cheung AM, Hanley DA, Boyd SK, Wong AKO, Papaioannou A, Rahme E, Goltzman D; CaMos Research Group. Differences in fracture prevalence and in bone mineral density between Chinese and White Canadians: the Canadian Multicentre Osteoporosis Study (CaMos). Arch Osteoporos 2020;15:147.

9. Sheu Y, Cauley JA, Wheeler VW, Patrick AL, Bunker $\mathrm{CH}$, Ensrud KE, Orwoll ES, Zmuda JM; Osteoporotic Fracture in Men (MrOS) Research Group. Age-related decline in bone density among ethnically diverse older men. Osteoporos Int 2011;22:599-605.

10. Kwok AW, Gong JS, Wang YX, Leung JC, Kwok T, Griffith JF, Leung PC. Prevalence and risk factors of radiographic vertebral fractures in elderly Chinese men and women: results of Mr. OS (Hong Kong) and Ms. OS (Hong Kong) studies. Osteoporos Int 2013;24:877-85.

11. Wáng YXJ, Diacinti D, Leung JCS, Iannacone A, Kripa E, Kwok TCY, Diacinti D. Much lower prevalence and severity of radiographic osteoporotic vertebral fracture in elderly Hong Kong Chinese women than in age-matched Rome Caucasian women: a cross-sectional stud. Arch Osteoporos 2021;16:174.

Cite this article as: Wáng YXJ, Xiao BH, Su Y, Leung JCS, Lam PMS, Kwok TCY. Fine-tuning the cutpoint T-score as an epidemiological index with high specificity for osteoporosis: methodological considerations for the Chinese population. Quant Imaging Med Surg 2022;12(2):882-885. doi: 10.21037/ qims-21-845
12. Su Y, Wang YX, Kwok TC. The predictive power of vertebral endplate/cortical fracture (ECF) for further osteoporotic fracture risk among community dwelling elderly Chinese. The 11th meeting of Chinese Society of Osteoporosis and Bone Mineral Research. Hangzhou, China. October 28-31, 2020.

13. Freitas SS, Barrett-Connor E, Ensrud KE, Fink HA, Bauer DC, Cawthon PM, Lambert LC, Orwoll ES; Osteoporotic Fractures in Men (MrOS) Research Group. Rate and circumstances of clinical vertebral fractures in older men. Osteoporos Int 2008; 19:615-23.

14. Lynn HS, Lau EM, Au B, Leung PC. Bone mineral density reference norms for Hong Kong Chinese. Osteoporos Int 2005;16:1663-8.

15. Zeng Q, Li N, Wang Q, Feng J, Sun D, Zhang Q, Huang J, Wen Q, Hu R, Wang L, Ma Y, Fu X, Dong S, Cheng X. The Prevalence of Osteoporosis in China, a Nationwide, Multicenter DXA Survey. J Bone Miner Res 2019;34:1789-97.

16. Iki M, Kagamimori S, Kagawa Y, Matsuzaki T, Yoneshima H, Marumo F. Bone mineral density of the spine, hip and distal forearm in representative samples of the Japanese female population: Japanese Population-Based Osteoporosis (JPOS) Study. Osteoporos Int 2001;12:529-37.

17. Kanis JA, Johnell O, De Laet C, Jonsson B, Oden A, Ogelsby AK. International variations in hip fracture probabilities: implications for risk assessment. J Bone Miner Res 2002;17:1237-44.

18. Kanis JA, Cooper C, Rizzoli R, Reginster JY; Scientific Advisory Board of the European Society for Clinical and Economic Aspects of Osteoporosis (ESCEO) and the Committees of Scientific Advisors and National Societies of the International Osteoporosis Foundation (IOF). European guidance for the diagnosis and management of osteoporosis in postmenopausal women. Osteoporos Int 2019;30:3-44.

19. Kwok TCY, Law SW, Leung EMF, Choy DTK, Lam PMS, Leung JCS, Wong SH, Ip TP, Cheung CL. Hip fractures are preventable: a proposal for osteoporosis screening and fall prevention in older people. Hong Kong Med J 2020;26:227-35. 


\section{Appendix 1 An example of calculation of T-score and cutoff BMD value for osteoporosis in Japanese}

\section{elderly women}

The data is from: Iki M, Kagamimori S, Kagawa Y, Matsuzaki T, Yoneshima H, Marumo F. Bone mineral density of the spine, hip and distal forearm in representative samples of the Japanese female population: Japanese Population-Based Osteoporosis (JPOS) Study. Osteoporos Int 2001;12:529-37.

1. Based on table-2 of the article, the mean BMD for women aged 50-79 yrs is calculated according to:

$$
B M D_{\text {mean }}=\frac{\sum_{1}^{6} n_{i}^{*} M_{i}}{\sum_{1}^{6} n_{i}}
$$

( $M_{\mathrm{i}}$ : mean BMD value of different age groups; $n_{\mathrm{i}}$ : subject number of different age groups) and 0.6569 is derived for Japanese old women.

2. The standard deviation (SD) is calculated according to:

$$
S D=\sqrt{\frac{\sum_{1}^{6}\left(n_{i}-1\right) * s_{i}^{2}}{\sum_{1}^{6} n_{i}-6}}
$$

$\left(s_{i}\right.$ : standard deviation of different age groups) and 0.0913 is derived for Japanese old women.

3. T-score is calculated according to

$$
T-\text { score }=\frac{B M D_{\text {measured }}-B M D_{\text {peak }}}{S D_{\text {peak }}}
$$

According to table-4, $\mathrm{BMD}_{\text {peak }}=0.801, \mathrm{SD}_{\text {peak }}=0.106$.

If T-score for defining osteoporosis is $\leq-2.5$, then the cutoff value of measured BMD is 0.5360 .

4. For elderly Japanese women, with mean BMD of 0.6569 and SD of 0.0913, a Gaussian distribution is shown in Figure S1.

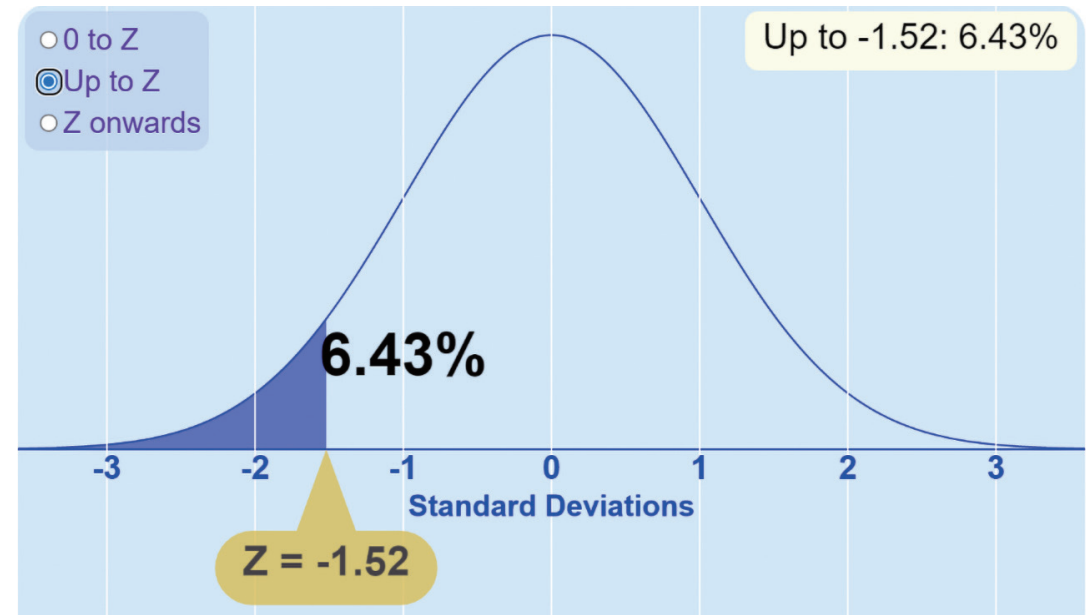

$\mathrm{Z}=\left(\mathrm{BMD}_{\text {measured }}\right.$ - age-matched population mean $\left.\mathrm{BMD}\right) /$ age-matched population $\mathrm{SD}=\left(\mathrm{BMD}_{\text {measured }}-0.6569\right) / 0.0913$.

If the hip fracture reference is approximately $6.43 \%$ (i.e., $40 \%$ of the Caucasian rate), then $Z=-1.52$ (based on Figure S1), and $\mathrm{BMD}_{\text {measured }}=0.5291$. This is the BMD cutoff point for defining osteoporosis, and the corresponding T-score is -2.5651 . 